Western University

Scholarship@Western

Department of Economics Research Reports

Economics Working Papers Archive

1982

\title{
The Size and Structure of Union-Nonunion Wage Differentials in Canadian Industry: Corroboration, Refinement and Extension
}

Glenn M. MacDonald

Follow this and additional works at: https://ir.lib.uwo.ca/economicsresrpt

Part of the Economics Commons

Citation of this paper:

MacDonald, Glenn M.. "The Size and Structure of Union-Nonunion Wage Differentials in Canadian Industry: Corroboration, Refinement and Extension." Department of Economics Research Reports, 8218. London, ON: Department of Economics, University of Western Ontario (1982). 
ISSN :

$0318-725 \mathrm{X}$

ISBN: $\quad 0-7714-0380-1$

\section{RESEARCH REPORT 8218}

THE SIZE AND STRUCTURE OF UNION-NONUNION WAGE DIFFERENTIALS IN CANADIAN INDUSTRY: CORROBORATION, REFINEMENT AND EXTENSION*

by

Glenn M. MacDonald

October, 1982

Revised September, 1982

Department of Economics library

Revised September, $1982 \quad$ Department of Economics Libran

* Barbara Mann, Christopher Robinson, Nigel Tomes and Michael

Veall contributed many helpful comments for which the author is appreciative. Irene Majski provided excellent research assistance. 


\section{INTRODUCT ION AND SUMMARY}

In the May 1981 issue of the Canadian Journal of Economics, John C. Evans and I (hereafter $M-E$ ) provided estimates of the size and structure of unionnonunion wage differentials in Canada. The basic approach involved estimation of a wage equation derived from the aggregation procedure used to construct industry average wage rates. Annual data on thirty manufacturing industries over the period 1971-76 were utilized.

Though our results were plausible, our method of handling one particularly serious shortcoming in the data (to be described below) prevented the estimates from being offered with great conviction. This paper incorporates two improvements: (i) the sample period is extended to 1979; and (ii) a more appropriate technique for solution of the aforementioned data difficulty is adopted.

The discussion of the results in M-E focussed on those aspects of the estimated differentials which (at least in the authors' view) could be relied upon most confidently: the basic structure and temporal variation of the differentials. The estimated average size of the differentials (58.1 percent, -1.5 percent and 29.0 percent for skilled, semi-skilled and unskilled workers respectively, with an overall average of 15.8 percent) appeared much less reliable.

The new estimates support this view. The conclusions concerning the structure and temporal variation of the differentials are re-affirmed; however the average size of the estimated differentials changed markedly. On the average the estimated union-nonunion differential is 19.5 percent, which can be decomposed into 22.3 percent, 16.3 percent and 25.3 percent for skilled, semiskilled, and unskilled workers respectively. 
Furthermore, the longer sample period covers the reign of the AntiInflation Board (AIB). The data herein indicate that if the AIB had not been formed, real wages would only have grown by about 1.2 percent more than they in fact did over the period spanned by the AIB. The AIB's impact on the union-nonunion wage differential was negligible.

The next section briefly reiterates the empirical model. The succeeding sections describe the major data problem and the proposed solution, and the new estimates.

\section{AN EMPIRICAL MODEL OF UNION-NONUNION WAGE DIFFERENTIALS}

The wage differentials are inferred from estimates of the parameters of a wage equation. The latter is arrived at via the aggregation procedure used to compute industry average wages.

Equilibrium wages for union $(u)$ and nonunion $(n)$ workers in skill group $s(s=1, \ldots, s)$ are assumed to depend on the characteristics of workers in each group $\left(x_{s}^{u}\right.$ and $\left.x_{s}^{n}\right)$ and characteristics of firms $(Y)$ as follows:

$$
\ln w_{s}^{n}=X_{s}^{n} \beta+Y \gamma
$$

and

$$
\ln w_{s}^{u}=X_{s}^{u} \beta+Y \gamma+\phi_{s}
$$

In (1), $\beta$ and $\gamma$ are vectors of parameters. Minor manipulation gives $\exp \left(\phi_{s}\right)-1$ as the percentage union-nonunion wage differential for skill group $s$. Let $\alpha_{s}$ and $u_{s}$ be the $s^{\text {th }}$ skill group's share of employment, and fraction unionized respectively. Then, using (1), the $\log$ of the geometric mean of wages can be written ${ }^{1}$

$$
\ln \overline{\mathrm{w}}=\overline{\mathrm{X}} \beta+\mathrm{Y} \gamma+\sum_{s=1}^{\mathrm{S}} \alpha_{s} \mathrm{u}_{s} \phi_{s},
$$


where $\overline{\mathrm{X}} \equiv \Sigma_{s=1}^{s} \alpha_{s}\left[u_{s} \mathrm{x}_{s}^{\mathrm{u}}+\left(1-u_{s}\right) \mathrm{x}_{s}^{n_{s}}\right]$ is a vector of industry average worker characteristics. $\phi_{s}$ is not required to be constant. Consequently, it is parameterized as

$$
\phi_{s}=z_{s} \delta_{s}
$$

where $Z_{S}$ may contain some elements of $\bar{X}$ and $Y$, and $\delta_{S}$ is a vector of parameters. The assumed error structure is of the additive variance components type. Appending this structure, and substituting (3) into (2) gives the equation to be estimated:

$$
\ell n \bar{w}_{i t}=\bar{x}_{i t} \beta+Y_{i t} \gamma+\sum_{s=1}^{s} \alpha_{s} u_{s t}\left(z_{i t} \delta_{s}\right)+\mu_{i}+\nu_{t}+\epsilon_{i t}
$$

In (4) $i(i=1, \ldots, 30)$ and $t(t=1971, \ldots, 1979)$ index industries and time respectively. $\mu_{i}$ captures industry specific wage variation which does not vary over time; time dependent wage shocks common to all industries are accounted for by $\nu_{t}$; and $\epsilon_{i t}$ is the standard error term.

\section{A DATA PROBLEM AND A SOLUTION}

Estimation of the parameters of (4) requires data on $u_{s}$. These data are unavailable. However, data on the fraction of workers unionized ( $\bar{u})$ can be obtained. These data may be employed to overcome the absence of full information on $u_{s}$ as follows. By definition,

$$
\dot{u}=\sum_{s=1}^{s} \alpha_{s} u_{s} \text {. }
$$

Assume $u_{s}$ can be written

$$
u_{s}=Q_{s} \varphi_{s}
$$

where $Q_{S}$ is a vector of exogenous variables and $\varphi_{S}$ is a vector of constants. Then, OLS estimation of

$$
\bar{u}=\sum_{s=1}^{s} \alpha_{s}\left(Q_{s} \varphi_{s}\right)
$$


yields estimates of $u_{s}: \hat{u}_{s}=Q_{s} \hat{\varphi}_{s}$ where $\hat{\varphi}_{s}$ are the oLs estimates of $\varphi_{s}$. $\hat{u}_{s}$ is used in place of $u_{s}$.

The simple economic theory underlying (4) implies the $u_{s}$ are endogenous. Conveniently, utilization of $\hat{u}_{s}$ in estimation of (4) approximates instrumental variables estimation if $Q_{s}$ contains exogenous variables distinct from $\bar{X}$ and $Y$. In $M-E$, in addition to all the other exogenous variables in the model $Q_{s}$ included the variable

$$
I^{*}=\left\{\begin{array}{rll}
1 & \text { if } & \bar{u}_{\text {it }} \geq u^{*} \\
-1 & \text { if } & \bar{u}_{\text {it }}<u^{*},
\end{array}\right.
$$

where $\mathrm{u}^{*}$ is union coverage averaged over industries and time. This approximates a "Wald type" instrumental variables estimator.

Here the difficulty arises. Despite Johnston's oft cited statement that "under fairly general conditions, the Wald estimator is consistent...", the requirements are in fact quite stringent (Neyman and Scott (1951)). Effectively, the variation in $u_{s}$ must be principally attributable to nonstochastic variables. While there is some, albeit indirect, evidence that this is the case $\left(\mathrm{R}^{2}\right.$ for the OLS estimation of (5) was .811 in M-E), utilization of Wald-type estimation is clearly a tenuous business; in retrospect, even the strong caveats expressed the "RESERVATIONS" section of M-E are probably insufficient. 2

The improvement introduced herein is as follows. Data on the distribution of workers in each skill group across three firm sizes has been constructed. $^{3}$ Let $\xi_{s}^{f}$ denote the fraction of workers in skill group s employed by firms of size $f(f=1,2,3) ; \Sigma_{f} \xi_{S}^{f}=1$. Then $\xi_{s}^{1}$ and $\xi_{s}^{2}$ can be included in $Q_{S}$. The estimates of (4) so obtained are effectively standard instrumental variables estimates. 
RESULTS OF THE IMPROVED ESTIMATION

As detailed in $M-E, \bar{X}$ is comprised solely of $F$, the fraction of workers in the industry who are female. Value added per man-hour, V, makes up $Y$. The determinants $\left(Z_{s}\right)$ of the differential $\phi_{s}$ are a constant, $F, V, \hat{u}_{s}$, labor's share of value added $(L)$, and a variable AIB, equal to the fraction of the year the AIB was in force. Finally, $Q_{s}$ contains a constant, $\ell_{n} V, F, L, \xi_{s}^{1}, \xi_{s}^{2}$, and AIB.

In the oLs estimation of (5), the $\xi_{s}^{f}$ variables are significant and quantitatively important determinants of $\hat{\mathrm{u}}_{\mathrm{s}} \cdot$ Accordingly, the important requirement (for estimation of (4)) that $\hat{u}_{s}$ display substantial variation independent of $\mathrm{V}, \mathrm{I}$ and $\mathrm{F}$ is satisfied.

Estimation of (4) yields the estimated union-nonunion differentials (standard errors of coefficients in parentheses) $:^{4}$

$$
\begin{aligned}
& \hat{\phi}_{1}=\frac{-.0626}{(.2210)}-\underset{(.0351)}{.0226 \mathrm{AIB}}+\underset{(.5623)}{.1432 \mathrm{~F}}+\underset{(.2757)}{.9902 \mathrm{~L}-} \stackrel{.1952}{(.1443)} \hat{\mathrm{u}}_{\mathrm{s}}
\end{aligned}
$$

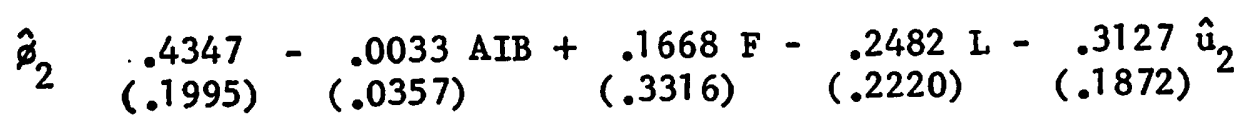

$$
\begin{aligned}
& \hat{\phi}_{3}=\underset{(.2086)}{-.9615} \underset{(.0352)}{.0095 \mathrm{AIB}}+\underset{(.2433)}{.5201} \mathrm{~F}+\underset{(.2094)}{.7888 \mathrm{~L}}+\underset{(.1768)}{1.031} \hat{\mathrm{u}}_{3}
\end{aligned}
$$

In terms of the signs of the coefficients determining the $\hat{\phi}_{s}$, the only noteworthy divergence between the results herein and those in $M-E$ is that the coefficient on $F$ changes sign and becomes significant in $\hat{\phi}_{3}$. In $\hat{\phi}_{2}$, both $L$ and $F$ also change signs, but neither is significant in either study. The basic character of the results on the structure of the differentials is unchanged, and thus neither are the conclusions drawn from them. 5 
Table 1 presents the time path of the $\hat{\phi}_{s}$, averaged over industries, and that of the grand average $\bar{\varnothing}=\Sigma_{s=1}^{s} \alpha_{s} \hat{\phi}_{s}$. The final column contains the estimates averaged over all years.

TABLE 1

Average Union-Nonunion Differentials by Skill and Year

$1971 \quad \underline{1972} \quad \underline{1973} \quad \underline{1974} \quad \underline{1975} \quad \underline{1976} \quad \underline{1977} \quad \underline{1978} \quad \underline{1979} \quad \underline{\text { Years }}$

skilled

$\begin{array}{llllllllll}.227 & .230 & .222 & .216 & .228 & .238 & .221 & .199 & .223 & .223\end{array}$

$\begin{array}{llllllllllll}\text { semi-skilled } & .163 & .164 & .171 & .175 & .158 & .152 & .144 & .163 & .172 & .163\end{array}$

$\begin{array}{lllllllllllll}\text { unskilled } & & .187 & .208 & .218 & .232 & .259 & .291 & .318 & .268 & .292 & .253\end{array}$

$\begin{array}{lllllllllllll}\text { average } & & .164 & .169 & .179 & .189 & .196 & .210 & .219 & .204 & .228 & .195\end{array}$

The all years figures are a good deal higher than those reported in M-E, and similar to recent results from analyses based on micro data. 6

The traditional hypothesis that union-nonunion differentials are negatively associated with changes in the rate of inflation can be examined slightly more systematically than was possible in $\mathrm{M}-\mathrm{E}$. The simple correlations between the proportional rate of change of $\hat{\phi}_{s}$ and proportional changes in the rate of inflation (as measured by the C.P.I.) are $.07,-.08$ and -.12 for the skilled, semi-skilled and unskilled respectively. The data do not lend any support to the hypothesis.

The AIB attempted to control wages from late 1975 until the spring of 1978. Manufacturing wages were the primary target of its efforts. Consequently if the AIB was at all effective, this should be clearly evidenced in these data. Further, as previous studies have all used the same data 
base (Labor Canada's large settlements data), the extension to an independent data set (based on the establishments survey) is of some importance. 7

First consider the impact of the AIB on union-nonunion wage differentials. If the AIB's actions were effective and totally unanticipated, that wages negotiated prior to these actions were exempted implies the union-nonunion wage differential should increase with the imposition of controls. If controls were anticipated, some narrowing of the differential prior to the introduction of controls is also expected. Referring to Table $I$ and equations (6), there is no evidence that the AIB had any noticeable effect on wage differentials.

Estimates of the $\nu_{t}$ in equation (4) shed further light on the AIB issue. Over the 1971-75 period, estimates of $\nu_{t}$ imply an annual average rate of growth of real wages of 2.1 percent. Had the AIB not been present, a further increase of 6.5 percent would have been expected over 1976-78. The actual estimated growth was 5.2 percent, implying a reduction in annual wage growth of about .5 percentage points ( 1.3 percent over two and a half years).

These results contrast with the estimates based on settlements data, which range from reductions of 4.5 percent to 2 percent.

Altogether, the results herein support the folklore that owing to the unexpected growth in real wages in 1976 (arising from the unexpectedly low rate of inflation) the AIB had no significant impact on wage rates. 8

SUMMARY

The research reported on in this note has improved upon $M-E^{\prime}$ 's work on the union-nonunion differential in two ways: more data have been examined, and an improved instrumental variables technique utilized to overcome the lack of data on a crucial variable. The qualitative results presented in M-E are not altered by the new estimates. However, the actual estimates of the unionnonunion wage differentials can now be offered more confidently: skilled 
workers - 22.3 percent; semi-skilled - 16.3 percent; unskilled - 25.3 percent; and all workers together -19.5 percent.

Extension of the data set through 1979 allowed examination of the impact of the Anti-Inflation Board. The data offer no support for the hypothesis that the AIB had any sizeable impact on wages.

In the final section of $M-E$, it was stated that the estimates offered therein were the authors' best efforts subject to the constraints of data availability; an example of optimizing behavior within the study of same. This note continues in the same self-referential vein by examining the gains associated with relaxation of a constraint, illustrating the Le Châtelier principle. 


\section{Footnotes}

${ }^{1}$ As the arithmetic mean is all that is available, that is what is utilized in the estimation reported on below. See MacDonald and Evans (1981, fn. 5).

${ }^{2}$ A second, less crucial, difficulty associated with utilization of $I^{*}$ is that $I^{*}$ does not vary across skill groups; there is really just one instrument where, in the usual case, identification requires three $Q_{s}$ does not vary with s). In principal, this is not problematic since I* enters (4) in a highly nonlinear fashion. Consequently, identification is achieved via nonlinearities. In practice, this approach does not perform well outside of large samples, and unless the issue of functional form is settled in advance. The improved approach does not rely on nonlinearities for identification.

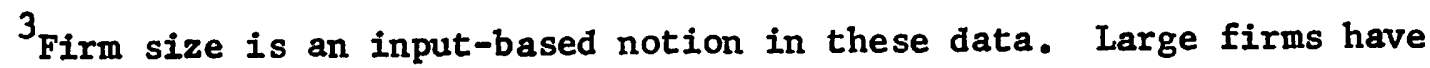
500 or more production employees; firms employing 100 to 499 are classed as medium sized; the rest are classified as small.

${ }^{4}$ Fixed effects variance components estimation is only slightly more complex than OLS. See M-E (1981, p. 221).

${ }^{5}$ All results reported in this section were also computed using the 1971-76 sample only. The point estimates were similar to those obtained for the full sample; the standard errors were of course somewhat larger. The changes in the estimated differentials are thus appropriately attributed to the improved method of handling lack of data on $u_{s}$. 
6 Robinson and Tomes (1982) find differentials of 17.0 percent, 20.0 percent and 35.7 percent for hourly paid males in the private sector when the estimation procedure does not take account of selectivity bias induced by sorting into union and nonunion groups. Correcting for selection bias raises the differentials to $28.0,32.0$ and 59.0 percent, respectively.

The somewhat erratic behavior of estimates based on micro data is well documented (Freeman (1983)) and remains something of an empirical puzzle.

${ }^{7}$ Previous studies are surveyed in Riddell and Smith (1982).

8The folklore was generously supplied by Ron Wirick. 


\section{References}

Freeman, R. B. "Longitudinal Studies of Trade Union Effects," Journal of Labor Economics 1 (January 1983).

Johnston, J. Econometric Methods. New York: McGraw-Hi11, 1972.

MacDonald, G. M. and Evans, J. C. "The Size and Structure of UnionNonunion Wage Differentials in Canada," Canadian Journal of Economics 14 (May 1981), 216-231.

Neyman, J. and Scott, E. L. "Consistent Estimates Based on Partially Consistent Observations," Econometrica 16 (January 1948), 1-32.

Ridde11, W. C. and Smith, P. M. "Expected Inflation and Wage Changes in Canada," Canadian Journal of Economics 15 (August 1982), 377-394.

Robinson, C. M. G. F. and Tomes, N. "Union Wage Differentials in the Public and Private Sectors : A Simultaneous Equation Specification," University of Western Ontario, September 1982. 